\title{
Preferences and attitudes of older adults of Bialystok, Poland toward the use of over-the- counter drugs
}

This article was published in the following Dove Press journal:

Clinical Interventions in Aging

\author{
Mateusz Cybulski' \\ Lukasz Cybulski² \\ Elzbieta Krajewska-Kulak' \\ Magda Orzechowska' \\ Urszula Cwalina ${ }^{3}$ \\ 'Department of Integrated Medical \\ Care, Faculty of Health Sciences, \\ Medical University of Bialystok, \\ Bialystok, Poland; ${ }^{2}$ National Security \\ Student, Faculty of Social Sciences, \\ University of Warmia and Mazury in \\ Olsztyn, Olsztyn, Poland; ${ }^{3}$ Department \\ of Statistics and Medical Informatics, \\ Faculty of Health Sciences, \\ Medical University of Bialystok, \\ Bialystok, Poland
}

Purpose: The aim of the study was to assess preferences and attitudes toward the use of over-the-counter (OTC) drugs among residents of Bialystok aged 60 or older.

Patients and methods: The study included 170 people, inhabitants of Bialystok aged over 60: 85 students of the University of a Healthy Senior and the University of Psychogeriatric Prophylaxis, and 85 students of the University of the Third Age in Bialystok. The study made use of a diagnostic survey conducted via a questionnaire prepared by the authors.

Results: The vast majority of respondents bought OTC drugs for own use. About one-third of the respondents from each analyzed group bought OTC drugs less often than once every 3 months. Over half of the respondents bought OTC drugs due to a cold. A majority of the respondents were of the opinion that OTC drugs should be sold only in pharmacies. Over $40 \%$ of seniors took 1 OTC drug regularly. Most respondents also took vitamins and supplements. The main sources of information on OTC drugs for the studied seniors were their doctor and pharmacist. Respondents did not always consult the treatment method with a doctor or pharmacist. Over half of the respondents familiarized themselves with the contents of the OTC drug package leaflet. Over three-quarters of the respondents were familiar with drug disposal methods; however, despite declarations of being familiar with these principles, a significant percentage did not bring back medication to a pharmacy or clinic, or threw the drugs into the trash.

Conclusion: Our study found that in our sample there were many OTC drug consumers who did not always demonstrate responsible attitudes toward using this group of drugs. Thus, older people should be educated on the possible adverse effects of taking OTC drugs without consulting a doctor or pharmacist as well as basic drug disposal principles. Furthermore, legislation should be introduced that will limit the wide availability of OTC drugs, particularly to the elderly; and thus, lower the costs of hospitalization and outpatient treatment of this age group. Also, a wider-reaching study should be conducted. It should include a larger group of elderly people as well as information on intake of prescribed medications in order to be able to determine the frequency of drug consumption in this population, as well as seniors' preferences and attitudes in this regard.

Keywords: elderly, geriatric pharmacology, nutritional supplements, polypharmacy, selfmedication, vitamins

\section{Introduction}

An aging population is a major social and health problem to public health. It is estimated that by $2050,80 \%$ of the population of middle-developed and low-developed countries will be more than 60 years old; ${ }^{1}$ while people aged 65 and over will account for more than $25 \%$ of Europe's population. ${ }^{2}$ It is estimated that by 2035 more than one-quarter 
of Poland's citizens will be over 65, and in 2060 Poland's population will be one of the oldest societies in Europe. ${ }^{3}$

The high demand for drugs is closely linked to the aging population. ${ }^{4}$ A specific feature of older adults is an increasing trend in multimorbidity, which involves the presence of two or more chronic diseases. ${ }^{5}$ It is estimated that multimorbidity is present in $62 \%$ of people aged $65-74$, and up to $81.5 \%$ of people over 85 years. $^{6}$

Self-medication with over-the-counter (OTC) drugs is defined as the consumption by patients of drugs not prescribed by a doctor for the treatment of untreated or unrecognized conditions. ${ }^{7}$ In recent years, a high intake of OTC drugs among older adults has been observed. ${ }^{8-12}$ Previous literature has shown that certain factors, such as female sex and higher education, are responsible for increased OTC drugs consumption. ${ }^{13}$ In addition, in the elderly, many diseases and chronic conditions are associated with the phenomenon of polypharmacy, ${ }^{14}$ which involves the consumption of more than five prescribed drugs. Consequently, polypharmacy is associated with OTC drugs use. ${ }^{15}$

On the pharmaceutical market there are nearly 100,000 OTC drugs. Their safe use depends largely on the ability of the consumers to properly understand and use OTC drugs, as well as prescription drugs. ${ }^{9}$ However, OTC drugs are a bit different because they do not require the doctor's permission to use them and thus impose more decision-making on them. ${ }^{16}$ Many hospitalizations and deaths among the elderly occur every year due to adverse drug events (ADEs) caused by drugs. ${ }^{16-19}$ Nonetheless, drug consumers often view OTC drugs as less risky and safer than prescription drugs. ${ }^{18}$ In particular, this applies to older adults. When reading informational leaflets on OTC drugs, consumers may often misunderstand the information that may contribute to the high number of adverse drug events occurring each year. ${ }^{16,18,19}$ Therefore, consumers of OTC drugs need sufficient health knowledge to reduce the risk of hazardous events due to the use of drugs that may result in death. Older people are particularly vulnerable to ADE risk due to aging factors. ${ }^{16}$ Currently, there is a risk of overuse of OTC drugs, especially analgesics, in the whole population, and especially among the elderly. ${ }^{20,21}$ These concerns lead to an assessment of the needs and outcomes of OTC drugs in different age groups, especially among older adults.

Patients' ability to "self-report" OTC drug use varies in the literature. Some studies have demonstrated a high level of understanding between self-reporting and other methods. ${ }^{22-24}$ Other studies have found less support for this practice. ${ }^{25}$ Pit et $\mathrm{al}^{26}$ showed that the accuracy and withdrawal of self-medication depend on a multitude of factors, such as the length of the withdrawal period and the drug class. The benefits of self-reporting may include the use of OTC drugs and asking patients for information about the use of these drugs, which is often not possible with other methods such as databases for pharmaceutical claims or biochemicals measures. $^{27}$

The aim of the study was to assess preferences and attitudes toward the use of OTC drugs among residents of Bialystok aged 60 or older. Furthermore, we decided to evaluate correlations between preferences and attitudes of older people toward the use of OTC drugs and the respondents' socio-demographic data (age, sex, group of origin).

\section{Patients and methods}

\section{Participants}

The study was conducted in 2 groups:

- Group I - students of the University of a Healthy Senior (UHS) and the University of Psychogeriatric Prophylaxis (UPP) (85 people, including 67 women (78.82\%) and 18 men $(21.18 \%)$ ), carried out at the Faculty of Health Sciences of the Medical University of Bialystok. The UHS was established in October 2013. Its main objectives include: promoting healthy lifestyle and healthy attitudes, expanding knowledge in the field of medical care improving the quality of life of older people, the use of modern methods of diagnostics and treatment, as well as the use of medications and dietary supplements, and pharmacoeconomics in diseases of older people; prevention of loneliness and social activation of older people. The curriculum of UHS is based on three main pillars: lectures, practical classes (exercises), and optional activities. Due to the large interest in the continuation of education and further broadening of knowledge of health of seniors, and in response to the needs of older inhabitants of Bialystok, the second stage of health education, the UPP, was inaugurated in the academic year 2015/2016. The key objectives of the project include promotion of a healthy lifestyle and healthy attitudes from the mental aspect, extending knowledge in the field of medical care to improve the quality of life of older people with mental disorders, the use of modern methods of diagnosis and treatment, the use of drugs in mental diseases of older people, prevention of loneliness and social exclusion, and social activation of older people. The classes are carried out in the form of lectures, where the main groups of mental diseases of older people are discussed. 
- Group II - students of the University of the Third Age in Bialystok (UTA) (85 persons, including 63 women (74.12\%) and 22 men (25.88\%)), which aims at stimulating personal development, intellectual agility and physical fitness, social activation of older people, promotion of gerontological prophylaxis, and actions for the benefit of older people and the disabled. Classes at UTA are carried out in the form of: lectures, optional classes, and classes in sections and teams of interest. Currently UTA has the following sections: painting, embroidery, ballroom dancing, gymnastics, swimming, chess and bridge, peer assistance, table tennis, editorship, but also a choir and theatre, as well as foreign languages courses English, German, French, and Esperanto.

The study included 170 people in total, residents of Bialystok, aged 60 and over: 130 women (76.47\%) and 40 men (23.53\%). In the group from UHS and UPP, the youngest respondent was 60 years old, while the oldest was 78 . The median age was 67.22 years. Among the students of UTA, the median age was 65.72 years; the youngest respondent was 60 , and the oldest 85 . The median age of the whole study group was 66.47 . In the study group, 80 people $(47.05 \%)$ probably lived alone (UHS/UPP $-\mathrm{n}=43,50.58 \%$; UTA $-\mathrm{n}=37$, $43.53 \%)$. The respondents' socio-demographic characteristics are shown in Table 1.

Another criterion for inclusion in the study, besides age and place of residence, were the absence of cognitive impairments in the respondents and written consent for participation in the study. Each respondent could withdraw at any time.

Selection of the respondents was intentional. The authors assumed that at least 150 fully completed questionnaires would be collected, 75 from each study group. Finally, 170 full surveys were collected. A greater number of research tool copies were distributed, but not all of the questionnaires were returned to the authors. Eventually, the group of UHS and UPP students included 150 seniors (response rate $-56.67 \%$ ), while the group of UTA students included 350 seniors $(24.29 \%)$.

\section{Measurements and procedure}

The study was performed from April to July 2017. The study design was cross-sectional. We used the diagnostic survey method with a proprietary questionnaire consisting of 23 single-answer and multiple-choice closed questions. The questions pertained to socio-demographic characteristics (sex, age, marital status, place of residence, education, financial status), the method and frequency of OTC drug purchase, the amount of OTC drugs consumed, reasons
Table I Respondents' socio-demographic characteristics

\begin{tabular}{|c|c|c|c|c|c|c|}
\hline \multirow[t]{2}{*}{ Feature } & \multicolumn{2}{|c|}{ UHS/UPP } & \multicolumn{2}{|c|}{ UTA } & \multicolumn{2}{|c|}{ Total } \\
\hline & $\mathbf{n}$ & $\%$ & $\mathbf{n}$ & $\%$ & $\mathbf{n}$ & $\%$ \\
\hline \multicolumn{7}{|l|}{ Gender } \\
\hline Women & 70 & 82.35 & 64 & 75.29 & 134 & 78.82 \\
\hline Men & 15 & 17.65 & 21 & 24.71 & 36 & 21.18 \\
\hline \multicolumn{7}{|l|}{ Age } \\
\hline$\leq 70$ years & 70 & 82.35 & 76 & 89.41 & 146 & 85.88 \\
\hline$\geq 71$ years & 15 & 17.65 & 9 & 10.59 & 24 & 14.12 \\
\hline \multicolumn{7}{|l|}{ Marital status } \\
\hline Married & 39 & 45.88 & 46 & 54.12 & 85 & 50.00 \\
\hline Widowed & 27 & 31.76 & 23 & 27.06 & 50 & $29.4 I$ \\
\hline Single & 2 & 2.35 & I & 1.18 & 3 & 1.76 \\
\hline Divorced & 14 & 16.47 & 13 & 15.29 & 27 & 15.88 \\
\hline Separated & 3 & 3.53 & 2 & 2.35 & 5 & 2.94 \\
\hline \multicolumn{7}{|l|}{ Financial situation } \\
\hline Very good & 5 & 5.88 & 5 & 5.88 & 10 & 5.88 \\
\hline Good & 33 & 38.82 & 34 & 40.00 & 67 & $39.4 I$ \\
\hline Rather good & 17 & 20.00 & 20 & 23.53 & 37 & 21.76 \\
\hline Average & 30 & 35.29 & 24 & 28.24 & 54 & 31.76 \\
\hline Rather bad & 0 & 0.00 & I & 1.18 & I & 0.59 \\
\hline $\mathrm{Bad}$ & 0 & 0.00 & 1 & 1.18 & I & 0.59 \\
\hline \multicolumn{7}{|l|}{ Education } \\
\hline Higher education & 37 & 43.53 & 40 & 47.06 & 77 & 45.29 \\
\hline Secondary & 40 & 47.06 & 36 & 42.35 & 76 & 44.71 \\
\hline Technical & 6 & 7.06 & 2 & 2.35 & 8 & 4.71 \\
\hline Vocational & 2 & 2.35 & 3 & 3.53 & 5 & 2.94 \\
\hline Primary & 0 & 0.00 & 4 & 4.71 & 4 & 2.35 \\
\hline Total & 85 & 100.00 & 85 & 100.00 & 170 & 100.00 \\
\hline
\end{tabular}

Abbreviations: UHS, University of a Healthy Senior; UPP, University of Psychogeriatric Prophylaxis; UTA, University of the Third Age.

for taking OTC drugs, intake of nutritional supplements by respondents, factors affecting their decision to buy OTC drugs, sources of obtaining information on OTC drugs, as well as seniors' opinions and attitudes toward basic safety principles on proceeding with OTC drugs (reading drug information leaflets found in the package, taking the suggested drug dosage, familiarity with drug disposal methods, how to proceed with expired or unnecessary drugs, OTC drug points of sale). The purpose of the study was not analysis or history of adverse events, management of drug-related injuries or parameters of awareness of self-medication or OTC medication. The questionnaire content for all sections was guided by the literature, but where none existed, items were created by drawing on researcher experience.

Respondents received paper copies of the questionnaire, which they filled out at home after receiving detailed information from members of the study team.

\section{Ethics}

The Bioethics Committee of the Medical University of Bialystok approved this study (statute no R-I-002/35/2017); participants provided written informed consent. 


\section{Statistical analysis}

Comparisons of two groups in terms of quantitative characteristics were done using Pearson's chi-square test and chi-square test with Yates correction. In the case of ordinal features, the U Mann-Whitney test was used. Statistical analysis was done with STATISTICA 12 software. Statistical significance was set at $p<0.05$.

\section{Results}

\section{Method of making decisions on purchasing OTC drugs}

UHS/UPP students as well as people aged 71 and older most often bought OTC drugs for own use, without consulting a doctor. UTA students, both women and men, as well as people aged up to 70 most frequently made a decision to buy OTC drugs in connection with a doctor's recommendation. Detailed numerical data are presented in Table 2.

\section{Characteristics of buying OTC drugs}

Results pertaining to older people's preferences and attitudes toward buying OTC drugs are detailed in Table 3. The vast majority of respondents bought OTC drugs for own use. Almost all seniors bought OTC drugs in pharmacies. Statistical analysis indicated statistically significant differences between the UHS/UPP group and the UTA group and purchasing OTC drugs at grocery stores. About one-third of the elderly respondents from each analyzed group bought OTC drugs less frequently than once every 3 months. Over half of the respondents bought OTC drugs due to a cold. Subsequent reasons for buying OTC drugs by the elderly included muscle and joint pain as well as headaches. There was a statistically significant difference between those aged under 71 and those 71 years and older and purchase of OTC drugs due to cystitis. The most frequently indicated factors determining OTC drug purchase by the respondents included: the possibility to purchase right away, OTC drug effectiveness, and a pharmacist's professional advice. Statistical analysis revealed statistically significant differences between the group of people under 71 and those over 71 years old and drug effectiveness as a factor determining OTC drug purchase. A majority of the respondents were of the opinion that OTC drugs should be sold only in pharmacies. We found statistically significant differences between UHS/UPP students and the UTA group, and the opinion that OTC drugs should be available only in pharmacies. Detailed results are presented in Table 3.

\section{Number of OTC drugs taken as well as use of vitamins and supplements}

The study results show that over $40 \%$ of the studied seniors, including over half of men, took 1 OTC drug regularly. In the studied group of 170 older people, 2 women under 71, who were UHS/UPP students, regularly took 10 or more OTC drugs. Most respondents also took vitamins and nutritional supplements (Table 4).

\section{Sources of information on OTC drugs}

The main sources of information on OTC drugs for the studied seniors were their doctor and pharmacist. UTA students, women, and those 71 or older preferred a doctor; while UHS/UPP students, men, and those under 71 preferred a pharmacist. Detailed information is presented in Table 5.

\section{Respondents' preferences and attitudes on the safety of OTC drug use}

The studied older people did not always consult the treatment method with a doctor or pharmacist. Their decision was dependent on the symptoms. Depending on symptom intensity, they either consulted the treatment method with a doctor or pharmacist, or made a decision on their own. It is worth emphasizing that half of the respondents aged 71 and over always consulted the treatment method with a doctor or pharmacist. Statistical analysis indicated a statistically

Table 2 Respondents' methods of making decisions on purchasing OTC drugs

\begin{tabular}{|c|c|c|c|c|c|c|c|c|c|c|c|c|c|c|c|}
\hline \multirow{2}{*}{$\begin{array}{l}\text { Method of making decisions on } \\
\text { purchasing OTC drugs }\end{array}$} & \multicolumn{2}{|c|}{ UHS/UPP } & \multicolumn{2}{|c|}{ UTA } & \multirow[t]{2}{*}{$p$-value } & \multicolumn{2}{|c|}{ Females } & \multicolumn{2}{|c|}{ Males } & \multirow[t]{2}{*}{$p$-value } & \multicolumn{2}{|c|}{$\leq 70$ years } & \multicolumn{2}{|c|}{$\geq 71$ years } & \multirow[t]{2}{*}{$p$-value } \\
\hline & $\bar{n}$ & $\%$ & $\bar{n}$ & $\%$ & & $\bar{n}$ & $\%$ & $\bar{n}$ & $\%$ & & $\bar{n}$ & $\%$ & $\bar{n}$ & $\%$ & \\
\hline $\begin{array}{l}\text { Always or almost always it is my } \\
\text { decision }\end{array}$ & 19 & 22.35 & 25 & 29.41 & 0.100 & 34 & 25.37 & 10 & 27.78 & 0.825 & 40 & 27.40 & 4 & 16.67 & 0.269 \\
\hline $\begin{array}{l}\text { More often out of my own need, } \\
\text { without consulting a doctor }\end{array}$ & 32 & 37.65 & 18 & 21.18 & & 40 & 29.85 & 10 & 27.78 & & 39 & 26.71 & II & 45.83 & \\
\hline $\begin{array}{l}\text { Usually in connection with a doctor's } \\
\text { recommendations }\end{array}$ & 23 & 27.06 & 32 & 37.65 & & 42 & 31.34 & 13 & 36.11 & & 48 & 32.88 & 7 & 29.17 & \\
\hline $\begin{array}{l}\text { Always or almost always in connection } \\
\text { with a doctor's recommendations }\end{array}$ & II & 12.94 & 10 & 11.76 & & 18 & 13.43 & 3 & 8.33 & & 19 & 13.01 & 2 & 8.33 & \\
\hline Total & 85 & 100.00 & 85 & 100.00 & & 134 & 100.00 & 36 & 100.00 & & 146 & 100.00 & 24 & 100.00 & \\
\hline
\end{tabular}

Abbreviations: OTC, over-the-counter; UHS, University of a Healthy Senior; UPP, University of Psychogeriatric Prophylaxis; UTA, University of the Third Age. 


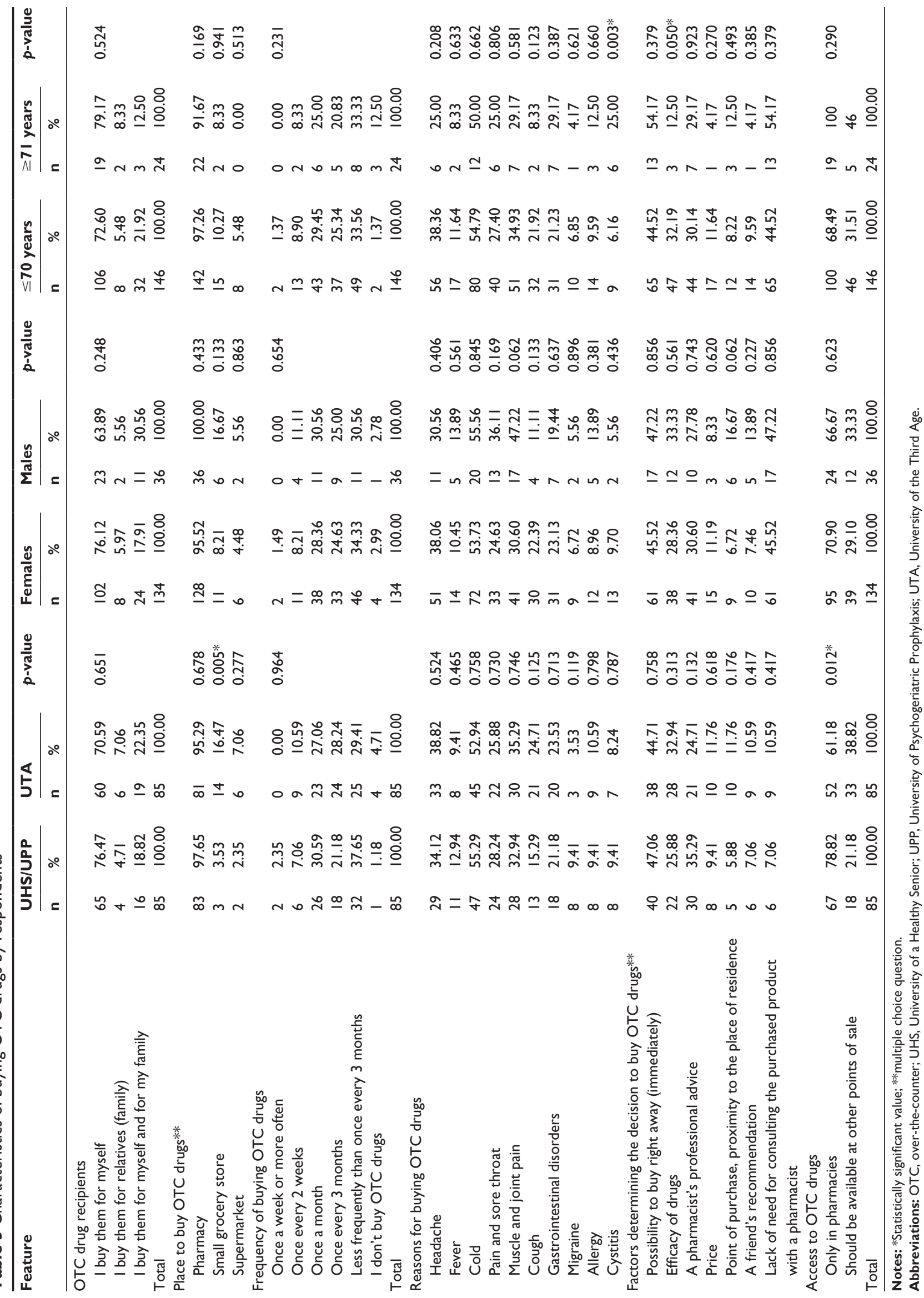


Table 4 Number of OTC drugs taken regularly as well as intake of vitamins and nutritional supplements by the respondents

\begin{tabular}{|c|c|c|c|c|c|c|c|c|c|c|c|c|c|c|c|}
\hline \multirow[t]{2}{*}{ Feature } & \multicolumn{2}{|c|}{ UHS/UPP } & \multicolumn{2}{|c|}{ UTA } & \multirow[t]{2}{*}{$p$-value } & \multicolumn{2}{|c|}{ Females } & \multicolumn{2}{|c|}{ Males } & \multirow[t]{2}{*}{ p-value } & \multicolumn{2}{|c|}{$\leq 70$ years } & \multicolumn{2}{|c|}{$\geq 71$ years } & \multirow[t]{2}{*}{$p$-value } \\
\hline & $n$ & $\%$ & $n$ & $\%$ & & $n$ & $\%$ & $n$ & $\%$ & & $n$ & $\%$ & $n$ & $\%$ & \\
\hline \multicolumn{5}{|l|}{ Number of drugs } & 0.442 & & & & & 0.129 & & & & & 0.891 \\
\hline 0 & 6 & 7.06 & 7 & 8.24 & & 10 & 7.46 & 3 & 8.33 & & 10 & 6.85 & 3 & 12.50 & \\
\hline 1 & 36 & 42.35 & 37 & 43.53 & & 54 & 40.30 & 19 & 52.78 & & 64 & 43.84 & 9 & 37.50 & \\
\hline 2 & 23 & 27.06 & 27 & 31.76 & & 40 & 29.85 & 10 & 27.78 & & 43 & 29.45 & 7 & 29.17 & \\
\hline 3 & 8 & 9.41 & 8 & 9.41 & & 14 & 10.45 & 2 & 5.56 & & 14 & 9.59 & 2 & 8.33 & \\
\hline 4 & 5 & 5.88 & 2 & 2.35 & & 7 & 5.22 & 0 & 0.00 & & 6 & 4.11 & I & 4.17 & \\
\hline 5 & 4 & $4.7 I$ & 3 & 3.53 & & 5 & 3.73 & 2 & 5.56 & & 5 & 3.42 & 2 & 8.33 & \\
\hline 6 & 0 & 0.00 & I & 1.18 & & 1 & 0.75 & 0 & 0.00 & & 1 & 0.68 & 0 & 0.00 & \\
\hline 7 & I & 1.18 & 0 & 0.00 & & I & 0.75 & 0 & 0.00 & & I & 0.68 & 0 & 0.00 & \\
\hline 10 and more & 2 & 2.35 & 0 & 0.00 & & 2 & 1.49 & 0 & 0.00 & & 2 & 1.37 & 0 & 0.00 & \\
\hline \multicolumn{5}{|c|}{ Intake of vitamins and supplements } & 0.616 & & & & & 0.935 & & & & & 0.068 \\
\hline Yes & 61 & 71.76 & 58 & 68.24 & & 94 & 70.15 & 25 & 69.44 & & 106 & 72.60 & 13 & 54.17 & \\
\hline No & 24 & 28.24 & 27 & 31.76 & & 40 & 29.85 & 11 & 30.56 & & 40 & 27.40 & 11 & 45.83 & \\
\hline Total & 85 & 100.00 & 85 & 100.00 & & 134 & 100.00 & 36 & 100.00 & & 146 & 100.00 & 24 & 100.00 & \\
\hline
\end{tabular}

Abbreviations: OTC, over-the-counter; UHS, University of a Healthy Senior; UPP, University of Psychogeriatric Prophylaxis; UTA, University of the Third Age.

significant difference between people under 71 and those aged 71 and over, and consulting treatment method with a doctor or pharmacist. Over half of the respondents familiarized themselves with the contents of the OTC drug package leaflet every time. The vast majority of respondents agreed with the statement that using active substances in higher doses than recommended can pose an immediate threat to human life or health. Over three-quarters of respondents were familiar with drug disposal methods. UHS/UPP students, women, and those aged 71 and older had more knowledge on this topic.

We found a statistically significant difference between UHS/UPP and UTW students and familiarity with drug disposal methods, as well as between the studied women and men and familiarity with drug disposal methods. Similar differences between the aforementioned groups were demonstrated in the case of proceeding with expired or unnecessary drugs. UHS/UPP students, women, and those aged 71 and older had more positive attitudes in this matter. Men and those under 71 years old sometimes returned drugs to a pharmacy or clinic. It is worth noting that despite declarations of being familiar with drug disposal principles, a significant percentage of respondents did not bring back medication to a pharmacy or clinic, or threw the drugs into the trash. Detailed results pertaining to the attitudes and preferences of older people in terms of drug use safety are presented in Table 6 .

\section{Discussion}

\section{Average OTC drug intake, including vitamins and supplements}

Despite widespread availability, OTC drugs can be both safe and effective if they are used correctly, that is according to a doctor's recommendations or as described in the package leaflet. ${ }^{28}$ According to Gallagher et al, ${ }^{29}$ elderly people consume on average $40 \%$ of the OTC drugs available on

Table 5 Sources of information on OTC drugs

\begin{tabular}{|c|c|c|c|c|c|c|c|c|c|c|c|c|c|c|c|}
\hline \multirow{2}{*}{$\begin{array}{l}\text { Sources of } \\
\text { information on } \\
\text { OTC drugs** }\end{array}$} & \multicolumn{2}{|c|}{ UHS/UPP } & \multicolumn{2}{|c|}{ UTA } & \multirow[t]{2}{*}{$p$-value } & \multicolumn{2}{|c|}{ Females } & \multicolumn{2}{|c|}{ Males } & \multirow[t]{2}{*}{$p$-value } & \multicolumn{2}{|c|}{$\leq 70$ years } & \multicolumn{2}{|c|}{$\geq 71$ years } & \multirow[t]{2}{*}{$p$-value } \\
\hline & $n$ & $\%$ & $n$ & $\%$ & & $n$ & $\%$ & $n$ & $\%$ & & $n$ & $\%$ & $n$ & $\%$ & \\
\hline Doctor & 39 & 45.88 & 42 & 49.41 & 0.645 & 63 & 47.01 & 18 & 50.00 & 0.750 & 7I & 48.63 & 10 & 41.67 & 0.527 \\
\hline Pharmacist & 41 & 48.24 & 40 & 47.06 & 0.878 & 60 & 44.78 & 21 & 58.33 & 0.148 & 72 & 49.32 & 9 & 37.50 & 0.283 \\
\hline Friends & 21 & 24.71 & 18 & 21.18 & 0.584 & 29 & 21.64 & 10 & 27.78 & 0.437 & 34 & 23.29 & 5 & 20.83 & 0.791 \\
\hline Family & 13 & 15.29 & 20 & 23.53 & 0.175 & 27 & 20.15 & 6 & 16.67 & 0.639 & 31 & 21.23 & 2 & 8.33 & 0.139 \\
\hline Internet & 21 & 24.71 & 25 & 29.41 & 0.490 & 34 & 25.37 & 12 & 33.33 & 0.340 & 41 & 28.08 & 5 & 20.83 & 0.459 \\
\hline Television & 9 & 10.59 & 14 & 16.47 & 0.262 & 15 & 11.19 & 8 & 22.22 & 0.086 & 19 & 13.01 & 4 & 16.67 & 0.628 \\
\hline $\begin{array}{l}\text { I don't look for } \\
\text { information - I } \\
\text { know what ails me }\end{array}$ & 16 & 18.82 & II & 12.94 & 0.294 & 22 & 16.42 & 5 & 13.89 & 0.712 & 21 & 14.38 & 6 & 25.00 & 0.187 \\
\hline Total & 85 & 100.00 & 85 & 100.00 & & 134 & 100.00 & 36 & 100.00 & & 146 & 100.00 & 24 & 100.00 & \\
\hline
\end{tabular}

Note: **Multiple choice question.

Abbreviations: OTC, over-the-counter; UHS, University of a Healthy Senior; UPP, University of Psychogeriatric Prophylaxis; UTA, University of the Third Age. 


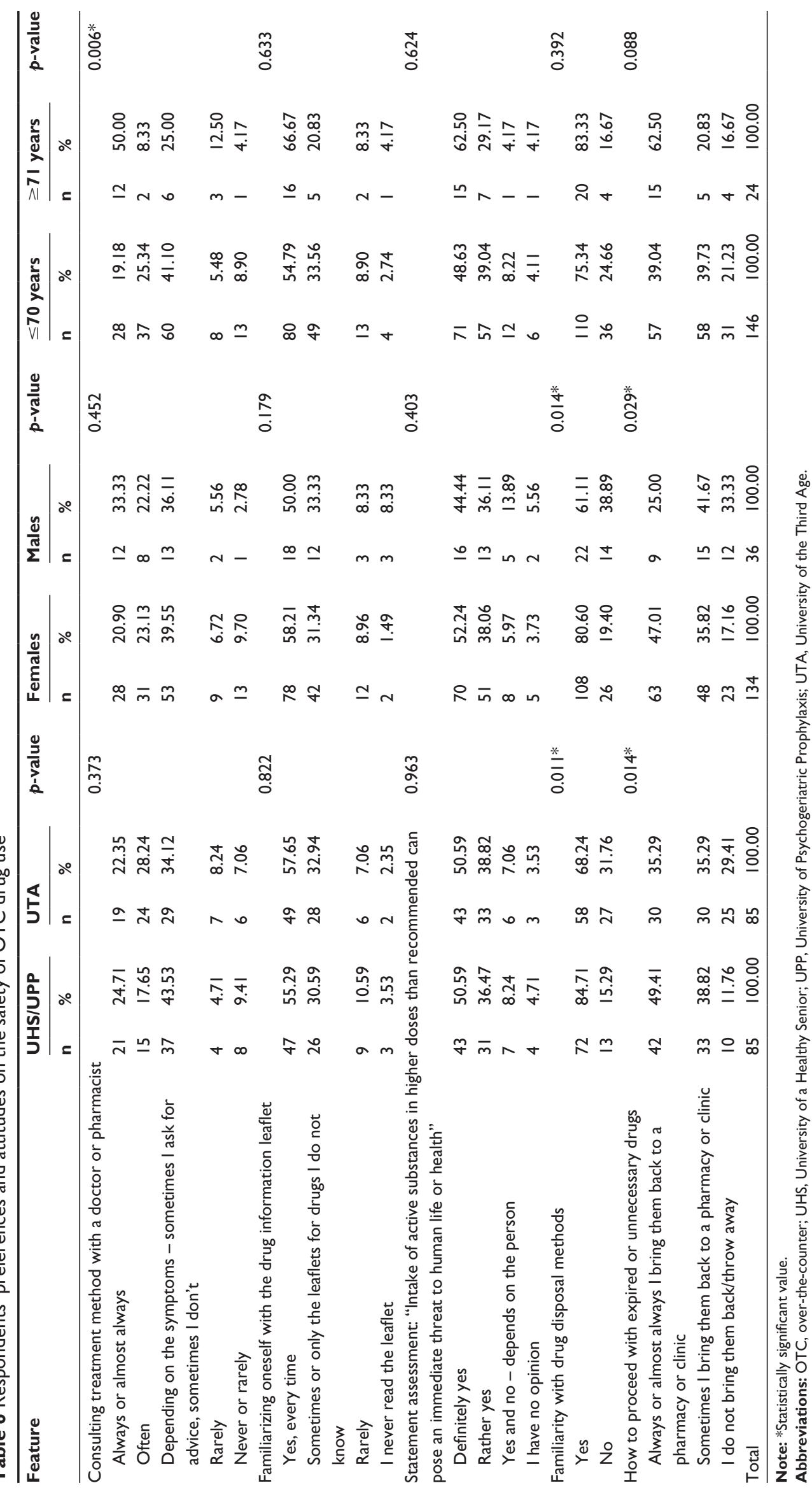


the market. Vitamins and nutritional supplements are popular medical preparations in this group of drugs. In our study, $70 \%$ of respondents declared taking vitamins and supplements. The value we obtained in our study was relatively high compared with other international surveys. Among the 112 elderly people surveyed in the USA, half of the seniors declared herbal supplement intake. In the group of elderly people taking herbal products, 59\% believed that consumption of these preparations in old age was safe. ${ }^{30}$ In a study by Yoon et al, $33 \%$ of 57 women had used one or more herbal products in the previous year. ${ }^{31} \mathrm{~A}$ Canadian study found that the highest frequency $(57 \%)$ of vitamin and supplement intake was among women aged 50-65 years. Calcium, iron, B vitamins, and glucosamine ${ }^{32}$ were the most often supplemented.

In our study, $43 \%$ of seniors took 1 OTC drug regularly. An identical percentage of women aged 65 and over, studied by Yoon et al, took an average of 2.6 OTC drugs. ${ }^{33}$ Canter and Ernst conducted a study in a group of 271 elderly people in Great Britain; they found that the respondents took an average of 2.26 prescription drugs and 5.91 supplements and herbal products. ${ }^{34}$ In a study conducted among 1,206 elderly people, Levine et $\mathrm{al}^{35}$ determined that half $(\mathrm{n}=616$, $51 \%$ ) had taken one or more nutritional supplement in the previous year. Moen et $\mathrm{al}^{36}$ found that $38.4 \%$ of the studied respondents took one or more OTC drug, while $8.3 \%$ took one or more herbal supplement. In a population of elderly primary health care patients in Germany, the average OTC drug intake was 1.4 preparations. ${ }^{37} \mathrm{~A}$ study of 3,072 outpatients aged 75 and older in the USA found that $82.5 \%$ of the studied cohort took at least one nutritional supplement, and $54.5 \% 3$ or more. ${ }^{38}$ In a study by Pannu et al, ${ }^{39} 81.5 \%$ of the respondents took at least one natural health product and $64.2 \%$ at least one OTC drug. In the USA, almost half of the elderly population regularly takes at least one OTC drug or supplement. ${ }^{40}$ Gazibara et $\mathrm{al}^{41}$ demonstrated that in a total of 354 elderly people included in the study, 202 seniors $(57.0 \%)$ stated taking OTC drugs in the previous month. Over half of the respondents (55.4\%) took 1 OTC drug, and the remaining $44.6 \%$ up to $5 .{ }^{41}$ A study conducted among a group of 975 elderly American women indicated that $82.2 \%$ of them took OTC drugs, and the average number of preparations taken was 1.8. ${ }^{42}$ These data illustrate the fact that OTC drug intake in our studied sample was on the lower end, and thus suggests a lower risk of polypharmacy occurrence in the elderly population.

\section{Reasons for OTC drug purchase}

The most frequent reasons the elderly gave for buying OTC medications included colds, muscle and joint pain, as well as headaches. Similar reasons for OTC drug purchase were indicated by Serbs - almost $40 \%$ of respondents bought an OTC drug to improve immunity and almost one-third for muscle and joint pain and headaches. ${ }^{41}$ These data point out that older people believe that OTC drugs improve health and eliminate unpleasant symptoms. In our study, as well as the aforementioned study conducted among seniors in Serbia, OTC drugs were mostly bought in pharmacies. ${ }^{41}$ Despite the wide availability of this group of drugs, elderly people generally decide to buy them from professionals.

\section{OTC drug intake and sex}

The obtained results prove that men were characterized by slightly lower intake of OTC drugs than women. Thus, they confirm trends described in previous studies; ${ }^{32,41,43-45}$ although our own research did not reveal such significant differences as previously published studies. Qato et $\mathrm{al}^{40}$ obtained similar results, in which women more often than men took nutritional supplements; however, general OTC drug intake was similar for both sexes (41.9\% for women and $42.6 \%$ for men). It is worth noting that in our study the percentage of participating men $(21.2 \%)$ was significantly lower than the percentage of participating women $(78.8 \%)$, which is the result of overrepresentation of elderly women compared with men in Poland. The higher OTC drug intake among women could also be caused by the fact that they might be supplementing certain minerals in accordance with a doctor's indications and principles of public health policy. Furthermore, women's more frequent visits in pharmacies and other OTC drug selling points may be determining factors in the higher intake in this group.

\section{Pharmacist as a source of information on OTC drugs}

Pharmacists are the best experts on OTC drug administration. Over $47 \%$ of respondents treated pharmacists as the main source of information on OTC medications. A similar percentage regularly consulted the treatment method with a doctor or pharmacist - it is worth noting that this percentage could and should be higher. This could be partially caused by older persons' belief that pharmacists are primarily responsible for all matters pertaining to prescribed medications, and not dispensing health advice and recommendations for OTC drugs and nutritional supplements. ${ }^{46}$

\section{Limitations of the study}

The conducted study had certain limitations. The study group was too small to be able to refer the results to the whole country. Respondents did not undergo an examination, 
nor were they asked in the questionnaire about drugs prescribed by a doctor or chronic diseases. In the future, a widerreaching study should be conducted, in which a bigger group of elderly people will be included, and which will also include history-taking on chronic diseases and taken prescription drugs, so that the obtained results could be representative for the elderly population in Poland.

\section{Conclusion}

Our study found that in our sample there were many OTC drug consumers who did not always demonstrate responsible attitudes toward using this group of drugs. Thus, older people should be educated on the possible adverse effects of taking OTC drugs without consulting a doctor or pharmacist as well as basic drug disposal principles. Furthermore, legislation should be introduced that will limit the wide availability of OTC drugs, particularly to the elderly; and thus, lower the costs of hospitalization and outpatient treatment of this age group. Also, a wider-reaching study should be conducted. It should include a larger group of elderly people as well as information on intake of prescribed medications in order to be able to determine the frequency of drug consumption in this population, as well as seniors' preferences and attitudes in this regard.

\section{Acknowledgments}

The research was funded under grant no N/ST/MN/17/001/ 3310 of the Ministry of Science and Higher Education. The funders had no role in study design, data collection and analysis, decision to publish, or preparation of the manuscript.

\section{Author contributions}

Mateusz Cybulski and Elzbieta Krajewska-Kulak contributed to the study design; Mateusz Cybulski, Lukasz Cybulski, and Magda Orzechowska contributed to data collection. All authors contributed toward data analysis, drafting, and critically revising the paper and agree to be accountable for all aspects of the work.

\section{Disclosure}

The authors report no conflicts of interest in this work.

\section{References}

1. Editorial. Ageing and health - an agenda half completed. Lancet. 2015; 386(10003): 1509 .

2. World Health Organization. The European Health Report 2012. Charting the Way to Well-Being. Copenhagen: WHO; 2013.

3. Mossakowska M, Wiecek A, Bledowski P, editors. Aspekty medyczne, psychologiczne, socjologiczne i ekonomiczne starzenia się ludzi w Polsce. [Medical, psychological, sociological and economic aspects of aging people in Poland]. Poznan: Wydawnictwa Medyczne Termedia; 2012. Polish.
4. National Institute on Aging, National Institutes of Health, World Health Organization. Global Health and Aging. Bethesda: NIA, NIH, WHO; 2011.

5. Ward BW, Schiller JS. Prevalence of multiple chronic conditions among US adults: estimates from the National Health Interview Survey, 2010. Prev Chronic Dis. 2013;10:E65.

6. Salive ME. Multimorbidity in older adults. Epidemiol Rev. 2013; 35(1):75-83.

7. AmoakoEP, Richardson-Campbell L,Kennedy-MaloneL. Self-medication with over-the counter drugs among elderly adults. J Gerontol Nurs. 2003;29(8):10-15.

8. González-Stuart A. Herbal product use by older adults. Maturitas. 2011;68:52-55.

9. Rolita L, Freedman M. Over-the-counter medication use in older adults J Gerontol Nurs. 2008;34(4):8-17.

10. Yoon SL, Schaffer SD. Herbal, prescribed, and over-the-counter drug use in older women: prevalence of drug interactions. Geriatr Nurs. 2006;27(2):118-129.

11. Willison KD, Andrews GJ. Complementary medicine and older people: past research and future directions. Complement Ther Nurs Midwifery. 2004; 10(2):80-91

12. MacLennan AH, Myers SP, Taylor AW. The continuing use of complementary and alternative medicine in South Australia: costs and beliefs in 2004. Med J Aust. 2006;184(1):27-31.

13. Peklar J, Henman MC, Richardson K, Kos M, Kenny RA. Food supplement use in the community dwelling population aged 50 and over in the Republic of Ireland. Complement Ther Med. 2013;21(4):333-341.

14. Salisbury C, Johnson L, Purdy S, Valderas JM, Montgomery AA. Epidemiology and impact of multimorbidity in primary care: a retrospective cohort study. Br J Gen Pract. 2011;61(582):e12-e21.

15. Goh LY, Vitry AI, Semple SJ, Esterman A, Luszcz MA. Self-medication with over-the-counter drugs and complementary medications in South Australia's elderly population. BMC Complement Altern Med. 2009;9:42

16. Albert SM, Bix L, Bridgeman M, et al. Promoting safe and effective use of OTC medications: CHPA-GSA National Summit. Gerontologist. 2014;54(6):909-918.

17. Maher RL, Hanlon J, Hajjar ER. Clinical consequences of polypharmacy in elderly. Expert Opin Drug Saf. 2014;13(1):57-65.

18. DeWalt DA. Ensuring safe and effective user of medication and healthcare: perfecting and dismount. JAMA. 2010;304(23):2641-2642.

19. Institutes of Medicine. To Err is Human: Building a Safer Health System. Washington: National Academies Press; 1999.

20. Turunen JH, Mäntyselkä PT, Kumpusalo EA, Ahonen RS. Frequent analgesic use at population level: Prevalence and patterns of use. Pain 2005;115(3):374-381.

21. Pokela N, Bell JS, Lihavainen K, Sulkava R, Hartikainen S. Analgesic use among community-dwelling people aged 75 years and older: A population-based interview study. Am J Geriatr Pharmacother. 2010; 8(3):233-244.

22. Stewart M. The validity of an interview to assess a patient's drug taking. Am J Prev Med. 1987;3(2):95-100.

23. Klungel OH, de Boer A, Paes AH, Herings RM, Seidell JC, Bakker A. Agreement between self-reported antihypertensive drug use and pharmacy records in a population-based study in the Netherlands. Pharm World Sci. 1999;21(5):217-220.

24. Haynes RB, Taylor DW, Sackett DL, Gibson ES, Bernholz CD, Mukherjee J. Can simple clinical measurements detect patient noncompliance? Hypertension. 1980;2(6):757-764.

25. Choo PW, Rand CS, Inui TS, et al. Validation of patient reports, automated pharmacy records, and pill counts with electronic monitoring of adherence to antihypertensive therapy. Med Care. 1999;37(9):846-857.

26. Pit S, Byles J, Cockburn J. Accuracy of telephone self-report of drug use in older people and agreement with pharmaceutical claims data. Drugs Aging. 2008;25(1):71-80.

27. Pit S, Byles J. Older Australians' medication use: self-report by phone showed good agreement and accuracy compared with home visit. JClin Epidemiol. 2010;63(4):428-434. 
28. American Geriatrics Society 2015 Beers Criteria Update Expert Panel. American Geriatrics Society 2015 updated Beers criteria for potentially inappropriate medication use in older adults. J Am Geriatr Soc. 2015;63(11):2227-2246.

29. Gallagher PF, Barry PJ, Ryan C, Hartigan I, O’Mahony D. Inappropriate prescribing in an acutely ill population of elderly patients as determined by Beers' Criteria. Age Ageing. 2008;37(1):96-101.

30. Snyder FJ, Dundas ML, Kirkpatrick C, Neill KS. Use and safety perceptions regarding herbal supplements: a study of older persons in southeast Idaho. J Nutr Elder. 2009;28(1):81-95.

31. Yoon SL, Horne CH, Adams C. Herbal product use by African American older women. Clin Nurs Res. 2004;13(4):271-288.

32. Troppmann L, Johns T, Gray-Donald K. Natural health product use in Canada. Can J Public Health. 2002;93(6):426-430.

33. Yoon SL, Horne CH. Perceived health promotion practice by older women: use of herbal products. Gerontol Nurs. 2004;30(7):9-15.

34. Canter PH, Ernst E. Herbal supplement use by persons aged over 50 years in Britain: frequently used herbs, concomitant use of herbs, nutritional supplements and prescription drugs, rate of informing doctors and potential for negative interactions. Drugs Aging. 2004;21(9): 597-605.

35. Levine MA, Xu S, Gaebel K, et al. Self-reported use of natural health products: a cross-sectional telephone survey in older Ontarians. Am J Geriatr Pharmacother. 2009;7(6):383-392.

36. Moen J, Antonov K, Larsson CA, et al. Factors associated with multiple medication use in different age groups. Ann Pharmacother. 2009;43(12):1978-1985.

37. Junius-Walker U, Theile G, Hummers-Pradier E. Prevalence and predictors of polypharmacy among older primary care patients in Germany. Fam Pract. 2007;24(1):14-19.
38. Nahin RL, Fitzpatrick AL, Williamson JD, et al. Use of herbal medicine and other dietary supplements in community-dwelling older people: baseline data from the ginkgo evaluation of memory study. J Am Geriatr Soc. 2006;54(11):1725-1735.

39. Pannu T, Sharkey S, Burek G, et al. Medication use by middle-aged and older participants of an exercise study: results from the Brain in Motion study. BMC Complement Altern Med. 2017;17:105.

40. Qato DM, Alexander GC, Conti RM, Johnson M, Schumm P, Lindau ST. Use of prescription and over-the-counter medications and dietary supplements among older adults in the United States. JAMA. 2008;300(24): 2867-2878.

41. Gazibara T, Nurkovic S, Kisic-Tepavcevic D, et al. Pharmacotherapy and over-the-counter drug use among elderly in Belgrade, Serbia. Geriatr Nurs. 2013;34(6):486-490.

42. Crentsil V, Ricks MO, Xue QL, Fried LP. A pharmacoepidemiologic study of community-dwelling, disabled older women: factors associated with medication use. Am J Geriatr Pharmacother. 2010;8(3):215-224.

43. Singh SR, Levine MA. Natural health product use in Canada: analysis of the National Population Health Survey. Can J Clin Pharmacol. 2006; 13(2):e240-e250.

44. Gardiner P, Graham R, Legedza ATR, Ahn AC, Eisenberg DM, Phillips RS. Factors associated with herbal therapy use by adults in the United States. Altern Ther Health Med. 2007;13(2):22-29.

45. Arcury TA, Grzywacz JG, Bell RA, Neiberg RH, Lang W, Quandt SA. Herbal remedy use as health self-management among older adults. J Gerontol. 2007;62B(2):S142-S149.

46. Abraham O, Schleiden LJ, Brothers AL, Albert SM. Managing sleep problems using non-prescription medications and the role of community pharmacists: older adults' perspectives. Int J Pharm Pract. 2017;25(6): 438-446.
Clinical Interventions in Aging

\section{Publish your work in this journal}

Clinical Interventions in Aging is an international, peer-reviewed journal focusing on evidence-based reports on the value or lack thereof of treatments intended to prevent or delay the onset of maladaptive correlates of aging in human beings. This journal is indexed on PubMed Central, MedLine,

\section{Dovepress}

CAS, Scopus and the Elsevier Bibliographic databases. The manuscript management system is completely online and includes a very quick and fair peer-review system, which is all easy to use. Visit http://www.dovepress. com/testimonials.php to read real quotes from published authors. 